\title{
Estándares convencionales en procedimientos de personas migrantes*
}

\author{
Conventional Standards in Procedures \\ of Migrant Persons
}

\section{Normes conventionnelles dans les procédures pour les migrants}

\section{Natalia Beltrán Orjuela** Leydi Marcela Palacios Segura***}

\begin{abstract}
SUMARIO: I. Introducción. II. Control de convencionalidad. III. Migrantes como sujetos de especial protección. IV. Estándares de protección de las personas en situación de migración. V. Conclusiones. VI. Bibliografía.
\end{abstract}

* Artículo de investigación resultado del proyecto de iniciación científica PIC-DER-2762, financiado por la Vicerrectoría de Investigaciones de la Universidad Militar Nueva Granada, vigencia 2018-II. Agradecemos al profesor Jesús Eduardo Sanabria y a la Vicerrectoría de Investigaciones de la Universidad Militar Nueva Granada por su valioso apoyo en el desarrollo de esta investigación.

** Universidad Militar Nueva Granada, Colombia; ORCID ID: https: / / orcid.org/0000-00022475-0098,nataliabeltraan@gmail.com.

*** Universidad Militar Nueva Granada, Colombia; ORCID ID: https: / / orcid.org/0000-00021757-8592.

Artículo recibido el 9 de mayo de 2020

Aprobado para publicación el 9 de octubre de 2020 
RESUMEN: El artículo aborda el estudio del control de convencionalidad directo realizado por la Corte Interamericana de Derechos Humanos, en relación con los derechos humanos a las garantías judiciales y protección judicial de las personas en calidad de migrantes. El resultado se obtiene a partir de una investigación básica jurídica, descriptiva y deductiva, que permite identificar los espacios convencionales generados a partir de espacios citacionales, los cuales se desarrollan en la función consultiva y contenciosa de la Corte Interamericana de Derechos Humanos.

Palabras clave: control de convencionalidad, migrantes, Corte IDH, derechos humanos, garantías judiciales, protección judicial.

ABSTRACT: This article focuses on the study of control of conventionality made by the InterAmerican Court of Human Rights regarding in relation to the human rights of judicial guarantees and judicial protection of persons as migrants. The result is obtained from a basic legal, descriptive, and deductive investigation that identifies the conventional spaces generated from citation spaces, which are developed in the advisory and contentious function of the InterAmerican Court.

Key words: control of conventionality, migrant, human rights, I/A Court HR, judicial guarantees, judicial protection.

RÉSUMÉ: Cet article se concentre sur l'étude du contrôle de la conventionalité faite par la Cour Interaméricaine des Droits de l'Homme en relation avec les droits humains des garanties judiciaires et de la protection judiciaire des personnes en tant que migrants. Le résultat est obtenu à partir d'une enquête juridique, descriptive et déductive de base qui identifie les espaces conventionnels générés à partir des espaces de citation, qui sont développés dans la fonction consultative et contentieuse de la Cour Interaméricaine.

Mots-clés: contrôle de la conventionalité, migrant, droits de l'homme, I/A Cour, garanties judiciaires, protection judiciaire. 


\section{INTRODUCCIÓN}

El control de convencionalidad encuentra su génesis en el derecho interno de los Estados, en particular, por medio del desarrollo del derecho constitucional francés. ${ }^{1}$ A nivel interamericano, la Corte Interamericana de Derecho Hunamos, en adelante Corte IDH o Corte Interamericana, es la encargada de velar por la vigencia y el cumplimiento de las obligaciones convencionales establecidas en el artículo 1.1 y 2o. de la Convención Americana sobre Derechos Humanos — en adelante, Convención Americana. De ahí el afán por establecer un marco mínimo de estándares comunes de protección de los derechos con ayuda de la actividad judicial de los Estados, en virtud de los principios de "buena fe, obligación jurídica pactada, de no anteponer el derecho interno al cumplimiento de obligaciones internacionales" ${ }^{\prime 2}$ del efecto útil de la Convención Americana.

Teniendo en cuenta lo anterior, el control de convencionalidad es "una actividad judicial de competencia de la Corte Interamericana de Derechos Humanos y de todos los jueces, tribunales, autoridades administrativas y legislativas de los distintos Estados parte de la Convención Americana, encaminada a la protección y efectividad de los derechos humanos", ${ }^{3}$ dsentro de los cuales se encuentran las garantías judiciales y la protección judicial, consagrados en los artículos 8o. y 25 de la Convención Americana, respectivamente.

Ambos derechos han sido analizados por la Corte IDH de forma conjunta en varias ocasiones, en específico, en materia de migrantes. A juicio de la propia Corte, ya las garantías y protección judiciales se relacionan al momento de verificar que en escenarios de acceso efectivo a la justicia,

1 Cubides Cárdenas, Jaime Alfonso, "El origen del control de convencionalidad (CCV) y sus implicaciones para los Estados que reconocen el sistema interamericano de derechos humanos (SIDH)", Ambiente Jurídico, vol. 15, 2013, pp.104-125.

2 Nogueira Alcalá, Humberto, "El control de convencionalidad por los Estados parte de la Convención Americana sobre Derechos Humanos y tribunales chilenos", Revista de Derecho (UCUDAL), vol. 15, núm. 1, 2017, p 148. Disponible en: http: / / www.scielo.edu.uy/pdf/rd/n15 12393-6193-rd-15-00143.pdf.

3 Quinche Ramírez, Manuel Fernando, El control de convencionalidad, Bogotá, Themis, 2014, p. 50. 
tanto los procedimientos judiciales ${ }^{4}$ como los recursos que contemplan y aplican los Estados en su interior, ${ }^{5}$ correspondan a los estándares mínimos de protección de los derechos humanos exigidos para esta población que sufre de una situación de vulnerabilidad frente a los nacionales de un Estado receptor.

En este orden de ideas, el presente artículo tiene como objetivo describir el control de convencionalidad directo en materia de los derechos humanos a las garantías judiciales y protección judicial de los migrantes en los procedimientos llevados a cabo en los Estados, a partir de la selección de opiniones consultivas y jurisprudencia de la Corte IDH en donde analiza las políticas y actuaciones de los Estados parte de la Convención Americana en relación con estos derechos.

En desarrollo del objetivo planteado, la metodología utilizada tiene como referencia una investigación descriptiva, jurídica y básica, por cuanto su finalidad es ampliar y profundizar el conocimiento de la realidad práctica, interpretativa y valorativa que hacen los jueces de la Corte Interamericana en uso de la figura jurídica del "control de convencionalidad directo" sobre las obligaciones convencionales de respeto, garantía, adecuación y no discriminación en lo relativo a los derechos de garantías judiciales y protección judicial de los migrantes.

La técnica utilizada consiste en la identificación de espacios citacionales, ${ }^{6}$ los cuales se definen como el grupo de sentencias que contienen una regla de derecho establecida por la Corte IDH frente a los derechos humanos en situaciones particulares. Al dar una significación a los espacios citacionales se encuentran los espacios convencionales, que definen los estándares establecidos por la Corte IDH para la protección de los derechos humanos.

4 Corte IDH, Caso Velásquez Rodríguez vs. Honduras. Excepciones Preliminares, Sentencia del 26 de junio de 1987, serie C, núm. 1, párr. 27.

5 Corte IDH, Caso Nadege Dorzema y otros vs. República Dominicana. Fondo, Reparaciones y Costas. Sentencia del 24 de octubre de 2012, serie C, núm. 251.

6 La técnica de la identificación de espacios citacionales es desarrollada por Eduardo López Medina, quien explica técnicas de análisis jurisprudencial en las sentencias de la Corte Constitucional de Colombia. El autor define nicho citacional como "zona de choque de intereses donde la Corte puede desplegar el análisis de la Constitución para encontrar balances que maximicen la protección de derecho. Entre todas estas zonas hay afinidades generales que se desprenden de elementos culturales, morales, políticos y económicos”. López Medina, Diego, El derecho de los jueces, Bogotá, Legis Editores, 2008, p. 400. 
El artículo, en primer lugar, explica la figura del control de convencionalidad. Posteriormente, se aborda el análisis de la situación de vulnerabilidad a la que están expuestos los migrantes en los Estados de recepción. Luego, estudia las decisiones en sede contenciosa y consultiva de la Corte IDH, en particular aquellas en las que realiza un control de convencionalidad directo con respecto a la normativa interna y las actuaciones del Estado, en el marco de un acceso efectivo a la justicia de los migrantes. Finalmente, identifica los espacios citacionales que se conforman a través de sus decisiones y los respectivos espacios convencionales que son auténticos estándares de protección, los cuales deben ser observados por los Estados con el fin de asegurar el pleno ejercicio de los derechos humanos en su jurisdicción, sin discriminación.

\section{CONTROL DE CONVENCIONALIDAD}

El control de convencionalidad se desarrolla en el sistema Interamericano de Derechos Humanos a partir de las decisiones de la Corte IDH, donde se verifica el cumplimiento de las obligaciones contenidas en la Convención Americana, por parte de los Estados. ${ }^{7}$ Esta figura se aborda desde de la Opinión Consultiva 14 de 1994, donde la Corte IDH explica la responsabilidad de los Estados por la expedición y la aplicación de normas contrarias a la Convención Americana, ${ }^{8}$ puntualizando que existe la obligación de dictar medidas necesarias para hacer efectivos los derechos y libertades, lo

7 La vocación institucional de la Corte IDH se materializa a través de pronunciamientos generales que consolidan ius commune interamericano en derechos humanos. Estas decisiones se conforman a partir de "enlaces" con las decisiones nacionales de los Estados parte de la $\mathrm{CADH}$, en aras de obtener una interpretación armónica del derecho a la luz de las normas interamericanas. Véase García Ramírez, Sergio, "Relación entre la jurisdicción interamericana y los Estados (sistemas nacionales). Algunas cuestiones relevantes”, Anuario Iberoamericano de Justicia Constitucional, núm. 18, 2014. Disponible en: https://dialnet.unirioja.es/servlet/ articulo? codigo $=4900203$.

8 La compatibilidad de las normas internas con la Convención Americana obedece al ejercicio que realiza la Corte IDH respecto a "leyes, Constitución Política..., proyectos de ley o proyectos de reforma constitucional” Roa, Jorge Ernesto, La función consultiva de la Corte Interamericana de Derechos Humanos, Bogotá, Universidad Externado de Colombia, 2015. 
cual comprende el deber de no dictarlas cuando ellas conduzcan a violar esas garantías. ${ }^{9}$

Por ende, en los casos fallados por la Corte IDH hasta 2004, se evidencia las declaratorias de responsabilidad internacional de los Estados parte por no adecuar su derecho interno a la Convención. Las primeras aproximaciones conceptuales se evidenciaron por parte del juez Sergio García Ramírez en sus votos razonados de los casos Myrna Mack y Tibi. ${ }^{10}$ Sin embargo, solo hasta el caso Almonacid Arellano vs. Chile, la Corte IDH hace referencia expresa al control de convencionalidad, explicando que "el Poder Judicial debe ejercer una especie de control de convencionalidad entre las normas jurídicas internas que aplican en los casos concretos y la Convención Americana sobre Derechos Humanos". ${ }^{11}$

De acuerdo con Quinche, el control realizado por la Corte IDH hasta 2004 puede ser denominado concentrado, en la medida que se trata de un control normativo que ejerce la Corte Interamericana, por el cual las normas de los distintos Estados parte son contrastadas desde la Convención Americana. De otro lado, desde la sentencia Almonacid Arellano, se evidencia un control de convencionalidad difuso, en el que no solo la Corte IDH ejerce control, sino que es una tarea que le compete, así como a los operadores jurídicos de los distintos Estados parte de la Convención. ${ }^{12}$

Así, a partir de la jurisprudencia referida, la Corte IDH ha explicado en qué consiste la figura y cuáles son sus elementos esenciales. El primero de ellos se describe en el caso Trabajadores Cesados del Congreso (Aguado Alfaro y otros) Versus Perú, en el cual la Corte IDH hace referencia a la obligación ex officio que tienen los jueces de los Estados parte de velar para que las decisiones judiciales sean conformes a la Convención. ${ }^{13}$ Esta concepción

9 Corte IDH, "Responsabilidad internacional por expedición y aplicación de leyes violatorias de la Convención (Arts. 1 y 2 Convención Americana sobre Derechos Humanos)", Opinión Consultiva OC-14/94, 9 de diciembre de 1994, serie A, núm. 14.

10 Corte IDH, Cuadernillo de Jurisprudencia de la Corte Interamericana de Derechos Humanos núm. 7 “Control de convencionalidad”, 2015.

11 Corte IDH, Caso Tibi vs. Ecuador. Excepciones Preliminares, Fondo, Reparaciones y Costas. Sentencia del 7 de septiembre de 2004, serie C, núm. 114, párr. 124.

12 Quinche Ramírez, Manuel Fernando, op. cit., p. 50.

13 Corte IDH, Caso Trabajadores Cesados del Congreso (Aguado Alfaro y otros) vs. Perú, solicitud de Interpretación de la Sentencia de Excepciones Preliminares, Fondo, Reparaciones y Costas. Sentencia del 30 de noviembre de 2007, serie C, núm. 174. 
se amplió en el caso Cabrera García y Montiel Flores vs. México, ${ }^{14}$ en el que se expresa que no solo los jueces, sino órganos vinculados a la administración de justicia en todos los niveles están en la obligación de ejercerlo. ${ }^{15}$ Adicionalmente, en los casos Gelman vs. Uruguay ${ }^{16}$, Personas Dominicanas y Haitianas expulsadas vs. República Dominicana ${ }^{17}$ y Rochac Hernández y otros vs. El Salvador, ${ }^{18}$ la Corte IDH determina que este control no le limita exclusivamente al Poder Judicial, puesto que es una función de todas las autoridades y órganos estatales. ${ }^{19}$

En el mismo sentido, se destaca que las obligaciones de los Estados de respetar y garantizar los derechos humanos no se limita a adecuar las normas según lo establece la Convención Americana, ya que se incluyen otros tratados internacionales que amplían la protección de las personas. Inclusive, la Corte IDH, en la Opinión Consultiva 21/14, determina la necesidad de que

Los diversos órganos del Estado realicen el correspondiente control de convencionalidad, también sobre la base de lo que señale en ejercicio de su competencia no contenciosa o consultiva, la que innegablemente comparte con su competencia contenciosa el propósito del sistema interamericano de dere-

14 Corte IDH, Caso Cabrera García y Montiel Flores vs. México. Excepción Preliminar, Fondo, Reparaciones y Costas. Sentencia del 26 de noviembre de 2010, serie C, núm. 220.

15 El control debe ejercerse "tanto en la emisión y aplicación de normas, en cuanto a su validez y compatibilidad con la Convención, como en la determinación, juzgamiento y resolución de situaciones particulares y casos concretos". Ibáñez Rivas, Juana María, "El control de convencionalidad y la consolidación del ius commune interamericano", en Von Bogdandy, Armin; Morales, Mariela y Ferrer Mac-Gregor, Eduardo (coords.), Ius constitutionale commune en América Latina. Textos básicos para su comprensión, México, Instituto de Estudios Constitucionales del Estado de Querétaro-Max Planck Institute for Comparative Public Law and International Law, 2017. Disponible en: http: / /www.corteidh.or.cr/tablas/r36072.pdf.

16 Corte IDH, Caso Gelman vs. Uruguay. Fondo y Reparaciones. Sentencia del 24 de febrero de 2011, serie C, núm. 221.

17 Corte IDH, Caso Personas dominicanas y haitianas expulsadas vs. República Dominicana. Excepciones Preliminares, Fondo, Reparaciones y Costas. Sentencia del 28 de agosto de 2014, serie C, núm. 282.

18 Corte IDH, Caso Rochac Hernández y otros vs. El Salvador. Fondo, Reparaciones y Costas. Sentencia del 14 de octubre de 2014, serie C, núm. 285.

19 Corte IDH, Cuadernillo de Jurisprudencia de la Corte Interamericana de Derechos Humanos núm. 7, cit. 
chos humanos, cual es, "la protección de los derechos fundamentales de los seres humanos". ${ }^{20}$

De esta forma, se evidencia que el control de convencionalidad es una herramienta efectiva para la protección de los derechos humanos, ya que no se limita exclusivamente a la confrontación entre normas nacionales y el corpus iuris interamericano adoptado en la región, ${ }^{21}$ sino que además analiza que las actuaciones de los Estados cumplan con las obligaciones que se desprenden de las fuentes interamericanas de derecho integradas, como la Convención Americana sobre Derechos Humanos, ${ }^{22}$ pues de ser incumplidas por un Estado parte generarían responsabilidad internacional.

Este procedimiento lo realiza la Corte IDH al estudiar los derechos de garantías judiciales y protección judicial, donde específicamente se analiza si los recursos judiciales suministrados por parte del Estado son efectivos ante una violación de derechos humanos (artículo 25) y si estos fueron sustanciados de conformidad con las garantías judiciales (artículo 8o.), dentro de las obligaciones generales de respetar y garantizar el libre y pleno ejercicio de los derechos ${ }^{23}$ en los procedimientos que involucren personas migrantes.

20 Corte IDH, "Derechos y garantías de niñas y niños en el contexto de la migración y/o en necesidad de protección internacional”, Opinión Consultiva OC-21/14 del 19 de agosto de 2014, serie A, núm. 21, párr. 31.

21 Instituto Interamericano de Derechos Humanos (IIDH), Manual auto-formativo para la aplicación del control de convencionalidad dirigido a operadores de justicia, Costa Rica, IIDH, 2015. Disponible en: http: / /www.corteidh.or.cr/tablas/32077.pdf.

22 Como regla general, los Estados deben cumplir las obligaciones contenidas en el artículo 1.1 y 2o. de la CADH. Sin embargo, de forma complementaria deben observar lo establecido en el artículo 29 y orientar sus actuaciones bajo el principio pro homine, así como cumplir con las decisiones de la Corte IDH en casos en los que hayan sido parte del proceso (art. 68 de la CADH). Cfr. González Domínguez, Pablo, "La doctrina del control de convencionalidad a la luz del principio de subsidiariedad”, Estudios Constitucionales, núm. 1, 2017. Disponible en: https: / /scielo.conicyt.cl/scielo.php?script=sci_arttext\&pid=S0718-52002017000100003.

23 Para el juez Ferrer Mac-Gregor el derecho a la protección judicial sirve como parámetro de constitucionalidad y de convencionalidad, y por esta razón propone un análisis novedoso e individual de este derecho. Cfr. Corte IDH, Voto Concurrente a la Sentencia de la Corte Interamericana de Derechos Humanos en el Caso Liakat Ali Alibux vs. Suriname. Excepciones Preliminares, Fondo, Reparaciones y Costas. Sentencia del 30 de enero de 2014, serie C, núm. 276, párr. 5. También véase Brewer, Allan y Santofimio Jaime, Control de convencionalidad y responsabilidad del Estado, Bogotá, Universidad Externado de Colombia, 2013, p. 384. 


\section{MigRANTES COMO SUJETOS DE ESPECIAL PROTECCIÓN}

La migración tiene un carácter multidimensional que impacta no solo a los países receptores, también a los países de origen y de tránsito. Al respecto, Naciones Unidas reconoce que estos factores requieren de respuestas integrales por parte de los Estados, destacando las contribuciones positivas que hacen los migrantes, tanto en los Estados de origen como de recepción. ${ }^{24}$ A pesar de que ello parezca revestir de la importancia necesaria por parte de los Estados, los flujos migratorios no siempre obtienen una respuesta favorable. Particularmente, Sergio García y Julieta Morales afirman que los problemas que se derivan de la migración irregular se enmarcan en un contexto singular que, a nivel americano, requiere de respuestas concretas. ${ }^{25}$

Ante esta situación, la Corte IDH, en su Opinión Consultiva 25, ha reiterado que los Estados deben cumplir con sus obligaciones internacionales sin tener en consideración el estatus migratorio de las personas. ${ }^{26}$ Para este tribunal:

La noción de igualdad se desprende de la unidad de naturaleza del género humano y es inseparable de la dignidad de la persona, frente a lo cual es incompatible toda situación que, por considerar superior a determinado grupo, conduzca a tratarlo como privilegio; o que, a la inversa por considerarlo inferior, lo trate con hostilidad o de cualquier forma lo discrimine del goce de sus derechos. ${ }^{27}$

24 Naciones Unidas, "Proyecto de Documento Final de la Reunión Plenaria de Alto Nivel de la Asamblea General Sobre la Respuesta a los Grandes Desplazamientos De Refugiados y Migrantes”, A/70/L.61, 2016. Disponible en: http://www.un.org/en/development/desa/popu lation/migration/generalassembly/docs/A_70_L.61_S.pdf.

25 García, Sergio y Morales, Julieta, "Afirmaciones y novedades en la jurisprudencia de la Corte Interamericana De Derechos Humanos (2009-2012)”, Anuario Iberoamericano de Justicia Constitucional, núm. 17, 2013. Disponible en: https://recyt.fecyt.es//index.php/AIJC/article/ viewFile/40786/23215.

26 Corte IDH, "La institución del asilo y su reconocimiento como derecho humano en el sistema interamericano de protección (interpretación y alcance de los artículos 5, 22.7 y 22.8 , en relación con el artículo 1.1 de la convención americana sobre derechos humanos)", Opinión Consultiva OC-25/18 del 20 de mayo de 2018, serie A, núm. 25.

27 Corte IDH, “Condición jurídica y derechos de los migrantes indocumentados”, Opinión Consultiva OC-18/03 del 17 de septiembre de 2003, serie A núm. 18, párr. 87. 
En el marco del derecho internacional, el principio de no discriminación hace parte del jus cogens. ${ }^{28}$ No obstante, los Estados tienen la potestad de regular su política migratoria, otorgando un trato diferenciado a los extranjeros que ingresan a su territorio, siempre que se ajuste a la Convención Americana. ${ }^{29}$ Esto significa que "el trato diferencial debe ser razonable, objetivo, proporcional y no debe lesionar los derechos humanos de los migrantes". ${ }^{30}$

Así las cosas, la Corte IDH reconoció por primera vez en su Opinión Consultiva sobre "Condición jurídica y derechos de los migrantes indocumentados", la situación de vulnerabilidad en la que se encuentran los migrantes en los Estados receptores, en específico, los trabajadores migratorios y sus familias. Al respecto, comenta que se fundamenta en las dificultades que tienen debido a su presencia o se acentúa tal estado de indefensión si es un migrante que se encuentra en situación irregular, de modo que los Estados no deben tolerar estas situaciones discriminatorias. ${ }^{31}$

Al mismo tiempo, ha establecido que los migrantes en situación irregular están expuestos a múltiples violaciones de sus derechos humanos a raíz de su nivel elevado de desprotección, el cual tiene su génesis en una dimensión ideológica que es mantenida por situaciones de jure (desigualdades entre nacionales y extranjeros en las leyes) y de facto (desigualdades estructurales). ${ }^{32}$

Bajo esta misma perspectiva, en el caso Vélez Loor vs. Panamá identifica que "los prejuicios culturales acerca de los migrantes permiten la reproducción de las condiciones de vulnerabilidad dificultando la integración de

28 Corte IDH, "La institución del asilo y su reconocimiento como derecho humano en el sistema interamericano de protección...”, cit., párr. 170.

29 Corte IDH, Caso Personas dominicanas y haitianas expulsadas vs. República Dominicana, cit., párr. 350. Cfr. García Ramírez, Sergio, op. cit., p. 249. Con la garantía del principio pro homine, el cual sobrepasa la esfera del derecho interno hacia su interpretación en el ámbito internacional. En este sentido, las políticas no deben restringirse a la norma constitucional sino avanzar hacia la protección internacional de los derechos.

30 Corte IDH, "La institución del asilo y su reconocimiento como derecho humano en el sistema interamericano de protección...”, cit., párr.119.

31 Corte IDH, “Condición jurídica y derechos de los migrantes indocumentados", cit., párr. 119.

32 Corte IDH, Caso Familia Pacheco Tineo vs. Bolivia. Excepciones Preliminares, Fondo, Reparaciones y Costas. Sentencia del 25 de noviembre de 2013, serie C, núm. 272, párr. 128. 
los migrantes a la sociedad". ${ }^{33}$ Tales prejuicios por lo general son étnicos, xenofóbicos y racistas. ${ }^{34}$ En igual sentido, la Corte IDH ha considerado que "la situación de vulnerabilidad se agrava debido a impedimentos normativos y fácticos que no permiten un acceso efectivo a la justicia". ${ }^{35}$

Respecto a este último punto, la Convención Americana sobre Derechos Humanos en sus artículos 8o. y 25 contiene los derechos humanos a las garantías judiciales y a la protección judicial, los cuales deben ser respetados y garantizados por las autoridades de Estados receptores y de tránsito de acuerdo con los estándares de protección que se derivan de la aplicación de la Convención Americana.

Así, la Corte IDH ha establecido que se vulnera el derecho a las garantías judiciales y a la protección judicial de los migrantes, en especial por los siguientes motivos: "Por el riesgo de la persona cuando acude a las instancias administrativas o judiciales de ser deportada, expulsada o privada de su libertad, y por la negativa de la prestación de un servicio público gratuito de defensa legal a su favor, lo cual impide que se hagan valer los derechos en juicio". ${ }^{36}$

Además, hace énfasis en la situación que presencian los migrantes en situación irregular. ${ }^{37} \mathrm{Al}$ respecto comenta que estos "no pueden acudir a los tribunales de justicia para reclamar sus derechos por temor a su situación irregular". ${ }^{38}$ A pesar de dichas circunstancias, le reitera a los Estados que los migrantes tienen derecho a acceder a un debido proceso legal en procedimientos que le afecten directamente. ${ }^{39}$

Precisamente, para la Corte IDH es pertinente señalar que se le debe garantizar a toda persona, extranjera o no, "el acceso a un recurso idóneo,

33 Corte IDH, Caso Vélez Loor vs. Panamá. Sentencia del 23 de noviembre de 2010, serie C, núm. 218, párr. 28.

34 Corte IDH, "Condición jurídica y derechos de los migrantes indocumentados", cit., párr. 113.

35 Corte IDH, Caso Nadege Dorzema y otros vs. República Dominicana, cit., párr. 153.

36 Corte IDH, "Condición jurídica y derechos de los migrantes indocumentados", op. cit., párr. 126.

37 Idem.

38 Ibidem, párr. 159.

39 En los casos de trabajadores migratorios, por ejemplo, tienen derecho de ser representados en un proceso laboral para que se le reconozca todo derecho que haya adquirido, pese a su estatus migratorio. Corte IDH, "Condición jurídica y derechos de los migrantes indocumentados", cit., párr. 121. 
sencillo y efectivo que lo ampare en la determinación de sus derechos". ${ }^{40}$ Este recurso no debe ser ilusorio y según la Corte IDH esto ocurre ante situaciones de denegación del acceso a la justicia. ${ }^{41}$

Por ello, es evidente que las garantías y la protección judiciales son derechos de observancia imperativa en todo proceso en donde se encuentren involucrados migrantes, cualquiera sea su condición migratoria, en términos de igualdad. ${ }^{42}$ En otras palabras, las normas de protección de los derechos humanos de los migrantes hacen parte de un corpus juris internacional ${ }^{43}$ con fundamento en las necesidades especiales que esta población requiere debido a su condición de vulnerabilidad en los Estados de acogida o de tránsito.

Por esta razón, los Estados tienen que abstenerse de realizar actuaciones que propicien o estimulen la mencionada vulnerabilidad y deben adoptar las medidas necesarias para prevenir y proteger los derechos de la población migrante ${ }^{44}$ en concreto a las garantías y a la protección judiciales.

\section{ESTÁNDARES DE PROTECCIÓN DE LAS PERSONAS}

EN SITUACIÓN DE MIGRACIÓN

Del análisis de las sentencias y opiniones consultivas emitidas por parte de la Corte IDH respecto a migrantes, se puede evidenciar que se realiza un control de convencionalidad directo de las disposiciones normativas y actuaciones de los Estados relacionadas con los derechos humanos contenidos en los artículos 8o. y 25 de la Convención Americana. A partir de ello, se permiten identificar los estándares de protección fijados por la Corte IDH cuando analiza la responsabilidad de los Estados frente a la existencia de recursos judiciales adecuados y efectivos, así como de las garantías judiciales conforme a la Convención Americana y otros tratados

40 Ibidem, párr. 107.

41 Ibidem, párr. 108.

42 Corte IDH, Caso Vélez Loor vs. Panamá, cit., párr. 132.

43 Corte IDH, "El derecho a la información sobre la asistencia consular en el marco de las garantías del debido proceso legal”, Opinión Consultiva OC-16/99 del 1 de octubre de 1999, serie A, núm. 16, párr. 4.

44 Corte IDH, Caso Vélez Loor vs. Panamá, cit. 
internacionales, en contextos de migración, que conforman los siguientes espacios citacionales y espacios convencionales: debido proceso en los procedimientos migratorios, asistencia consular y garantías de los niños y niñas en procedimientos migratorios:

\section{Debido proceso en los procedimientos migratorios}

La Corte IDH establece que si bien, los Estados tienen la facultad de establecer su política migratoria, esta debe ser conforme a la Convención Americana, de tal forma que respeten y garanticen los derechos humanos de las personas migrantes. En tal sentido, pueden presentarse procedimientos que culminen en una deportación, expulsión o solicitud de estatuto de refugiado, que deben cumplir con todas las garantías del debido proceso. ${ }^{45}$

En primer lugar, en el caso Vélez Loor vs. Panamá, la Corte IDH establece que, en casos de deportación, expulsión o privación de la libertad con carácter punitivo de un extranjero, "la asistencia jurídica gratuita se vuelve un imperativo de interés de la justicia". ${ }^{46}$

En este contexto, las garantías mínimas que se deben otorgar a este tipo de población son, en específico bajo el lineamiento del debido proceso legal, "el conjunto de requisitos que deben observarse en las instancias procesales, a efecto de que las personas se puedan defender adecuadamente ante cualquier acto del Estado que pueda afectarlos, independiente de su estatus migratorio". ${ }^{47}$

En cuanto a los recursos disponibles en los Estados, la Corte Interamericana reitera que es necesario probar su efectividad. Así, para que los migrantes gocen de un acceso efectivo a la justicia, los Estados deben garantizarles la asistencia letrada, ejercida por un abogado, puesto que los extranjeros no conocen el sistema legal del país en el que se encuentran y agrava su situación de vulnerabilidad. Aunado a ello, "impedirle el acceso

45 Corte IDH, Cuadernillo de Jurisprudencia de la Corte Interamericana de Derechos Humanos núm. 2, "Migrantes", 2015.

46 Corte IDH, Caso Vélez Loor vs. Panamá, cit., párr. 146.

47 Corte IDH, "Condición jurídica y derechos de los migrantes indocumentados", cit., párr. 122. 
a contar con la asistencia de su abogado defensor limita severamente el derecho de defensa, lo que ocasiona un desequilibro procesal al dejar al individuo sin tutela frente al ejercicio del poder punitivo". ${ }^{48}$

Al mismo tiempo, en el caso Nadege Dorzema vs. República Dominicana, la Corte IDH analiza las garantías mínimas individuales del debido proceso en casos de deportación y expulsión de migrantes de su territorio, cualquiera sea su condición jurídica, en virtud del respeto de la dignidad humana y el apego estricto a las garantías del debido proceso.

Estableció que el debido proceso debía respetar el principio de igualdad ante la ley y los tribunales, y la prohibición de discriminación, pues es una garantía que debe reconocérsele a todo migrante sin importar su estatus migratorio, ya que el alcance de este derecho no solo se aplica ratione materiae sino también ratione personae. ${ }^{49}$

En cuanto a las garantías que deben concederles los Estados a los individuos sujetos a un proceso de expulsión o de deportación, la Corte IDH hace referencia al Pacto Internacional de Derechos Civiles y Políticos, y a la Carta Africana de Derechos Humanos y de los Pueblos al considerar que deben ajustarse a las siguientes prerrogativas:

(i) Sólo podrá expulsarse a un extranjero en cumplimiento de una decisión adoptada conforme a la ley. (ii) Se debe facultar al extranjero a exponer las razones que lo asistan en contra de su expulsión; someter su caso a revisión de una autoridad competente y hacerse representar con tal fin ante ellas. (iii) Condiciones mínimas de detención durante el procedimiento. (iv) Acceso efectivo a la asistencia consular. (v) Derecho de ser representado ante autoridad competente. (vi) Derecho a contar con asistencia gratuita de un intérprete. (vii) Derecho a ser notificado de la decisión de expulsión y recurrirla. ${ }^{50}$

Por otra parte, en el caso Personas Dominicanas y Haitianas vs. República Dominicana, la Corte IDH estableció que los Estados tienen la obligación de

48 Corte IDH, Caso Vélez Loor vs. Panamá, cit., párr.132.

49 Corte IDH, Caso Nadege Dorzema y otros vs. República Dominican, cit.

50 Ibidem, párr. 162. En el caso concreto, se declaró responsable internacionalmente a República Dominicana porque no demostró la existencia de razones formales para proceder con la expulsión de los migrantes haitianos, así como no acreditó la existencia de un procedimiento que observara las garantías mínimas individuales del debido proceso que exige el artículo 8o. de la Convención Americana para estas situaciones en particular. 
garantizar un debido proceso sin importar el estatus migratorio, haciendo énfasis que las prerrogativas contenidas en el artículo 8o. de la Convención Americana, no se limitan a procesos judiciales, sino comprenden cualquier proceso, incluyendo aquellos administrativos o sancionatorios. ${ }^{51}$

A partir de lo anterior, retoma las garantías definidas en el caso Nadege Dorzema y las sintetiza en tres condiciones que deben cumplir los Estados: i) notificar a las personas acerca del proceso, con el fin de que sean informadas, puedan oponerse a los cargos y acceder a la asistencia consular; ii) someter el caso a revisión de autoridad competente, y iii) notificar la decisión, que debe ser motivada conforme a la normativa interna y los estándares internacionales de protección. ${ }^{52}$

A su vez, en este caso la Corte IDH determina, en relación con los recursos con los que cuentan los migrantes para recurrir este tipo de decisiones, que no basta con estar establecidos en la ley, pues los Estados deben garantizar que estos sean realmente accesibles por parte de las personas para la defensa de sus derechos afectados.

Por otra parte, en el caso Familia Pacheco Tineo vs. Bolivia la Corte Interamericana hace referencia a aquellos procedimientos que pueden terminar con una orden de expulsión o deportación de los migrantes, los cuales deben observar las garantías mínimas del debido proceso. Al respecto establece que estos procedimientos deben ser de carácter individual en el sentido de que evaluarán las circunstancias personales de cada extranjero, sin discriminación. ${ }^{53}$

No obstante, la Corte IDH, en su Opinión Consultiva 25, no se limita a explicar estos procedimientos, sino que determina en particular las garantías que se deben tener en cuenta cuando el migrante alega un peligro en caso de su devolución, ya sea en el marco de la Convención Americana o la Convención Interamericana para Prevenir y Sancionar la Tortura. Respecto a este punto, el Estado tiene el deber de por lo menos entrevistar a la persona que lo alega y realizar una evaluación previa para determinar si existe

51 Corte IDH, Caso Personas dominicanas y haitianas expulsadas vs. República Dominicana, cit. En el marco de los hechos del caso, la Corte Interamericana evidencia que si bien República Dominicana contaba en su normativa interna con disposiciones que establecían el procedimiento de deportación, estas no se cumplieron ni se llevaron a cabo, por cuanto el Estado, incumplió con su obligación de respeto y con ello vulneró el artículo 8o. de la Convención Americana.

52 Corte IDH, Caso Nadege Dorzema y otros vs. República Dominicana, cit.

53 Corte IDH, Caso Familia Pacheco Tineo vs. Bolivia, cit., párr. 159. 
o no el mencionado riesgo, observando las garantías mínimas del debido proceso, prohibiendo con ello la tortura u otros tratos crueles, inhumanos o degradantes y garantizando la protección de los derechos a la vida y a las garantías judiciales de los migrantes. ${ }^{54}$

Adicional a ello, el principio de no devolución es amplio y tiene diferentes matices. La Corte IDH estableció que “este principio constituye una norma consuetudinaria de derecho internacional y se ve reforzado por el reconocimiento a buscar y recibir asilo". ${ }^{55}$ Así, de la mano de los artículos 8o. y 25 de la Convención y tomando en consideración las directrices del Alto Comisionado de las Naciones Uinidas para los Refugiados (ACNUR), se garantiza que los solicitantes de asilo sean oídos con las debidas garantías legales dentro de un procedimiento justo y eficiente, que logre determinar la necesidad de protección a través de un correcto examen de su solicitud, por lo que se prohíbe que sean rechazados en la frontera o devueltos a su país de nacionalidad o residencia, sin un análisis adecuado e individualizado de sus peticiones. ${ }^{56}$

En atención a las necesidades de protección que requieren los migrantes que se enfrentan a procedimientos de carácter administrativo, la Corte IDH ha dispuesto un cúmulo de garantías que los Estados deben observar cuando se esté frente a estos casos, de la siguiente forma: 1) deben garantizar los servicios de un intérprete competente, el acceso a la asesoría y representación legal para la presentación de la solicitud y se le debe dar la oportunidad de ponerse en contacto con un representante del ACNUR; 2) la solicitud se examinará con objetividad, de acuerdo con un procedimiento preestablecido y la realización de una entrevista personal; 3) las decisiones deben estar fundamentadas de forma expresa; 4) debe garantizar la protección de los datos del solicitante y de la solicitud bajo el principio de confidencialidad; 5) si la decisión es desfavorable, se le debe permitir recurrir el fallo dentro de un plazo razonable, y 6) los recursos de revisión y apelación se concederán en efecto suspensivo y se le debe permitir al solicitante que permanezca en el país hasta tanto se resuelvan. ${ }^{57}$

54 Corte IDH, "La institución del asilo y su reconocimiento como derecho humano en el sistema interamericano de protección...”, cit., párr. 181.

55 Corte IDH, Caso Familia Pacheco Tineo vs. Bolivia, cit., párr. 151.

56 Idem.

57 Ibidem, párr. 159. 
Aunado a lo anterior, en virtud del artículo 25 de la Convención Americana sobre Derechos Humanos, también se pueden presentar otros recursos, como el amparo o el habeas corpus, que sean adecuados y efectivos para cuestionar la posible vulneración de sus derechos. ${ }^{58}$ Además, "es necesario determinar si los recursos existen y si es realmente posible ejercerlos en el contexto de la situación del país, de los hechos del caso o de la situación particular de las víctimas". ${ }^{59}$

Bajo esta misma línea, se hace hincapié que en situaciones en donde se presenten solicitudes manifiestamente infundadas o abusivas, esta Corte ha determinado que los Estados pueden adoptar procedimientos rápidos o acelerados, puesto que no se evidencia la necesidad de protección internacional para las personas que la solicitan. ${ }^{60}$

Respecto al marco fáctico del caso, la Corte IDH evaluó el comportamiento de las autoridades migratorias competentes y determinó que no se encontró demostrado que se haya realizado la correspondiente evaluación del riesgo de devolución a la familia, así como tampoco se les permitió expresar las razones de su instancia irregular en el país, no se llevó a cabo la entrevista personal u otro mecanismo que pudiera recolectar pruebas, ni se les brindó la posibilidad de controvertir la decisión que contenía posibles violaciones al debido proceso y al principio de no devolución (non refoulement), pues jamás se les notificó. También evidenció que no tuvo en cuenta el interés superior de los niños involucrados ${ }^{61}$.

Por último, dentro de este espacio convencional, resulta particular el casoWong HoWing vs. Perú, toda vez que, en él, si bien la Corte IDH retoma la obligación de garantizar el debido proceso en procedimientos que terminen con la deportación o expulsión de un migrante del Estado parte, analiza en

58 Idem.

59 Ibidem, párr. 191.

60 Corte IDH, Caso Familia Pacheco Tineo vs. Bolivia, cit. Si bien es cierto, en este caso el Estado de Bolivia aseguró que la familia Pacheco Tineo no había demostrado ningún riesgo de devolución, adujo, asimismo, que se encontraban frente a la cláusula de exclusión 1.f.b de la Convención sobre el Estatuto de Refugiados, por lo que argumentó que la solicitud de asilo era manifiestamente infundada y por ello se decidió de manera rápida.

61 De esta manera, el Estado no brindó las garantías mínimas que deben aplicarse en estos casos de acuerdo con la Convención Americana y el estándar establecido por esta Corte, y como consecuencia el Estado de Bolivia fue condenado. Véase Corte IDH, Caso Familia Pacheco Tineo vs. Bolivia, cit. 
particular el proceso de extradición, determinando si en el marco del proceso, el Estado de Perú respetó la garantía del plazo razonable, el derecho a ser oído y a la defensa. Este proceso es definido como "un mecanismo de cooperación internacional, el cual puede afectar derechos por lo que el Estado debe velar por respetar las garantías teniendo en cuenta los aspectos políticos y jurídicos". ${ }^{62}$

En cuanto al plazo razonable, analiza cada uno de los elementos que lo configuran. En este escenario determina que las relaciones diplomáticas existentes entre los Estados significan un asunto complejo, teniendo en cuenta la diferencia del idioma y del sistema jurídico. Sin embargo, los Estados deben actuar con debida diligencia y celeridad, de tal forma que puedan solicitar adecuadamente información y garantías diplomáticas en un tiempo que no genere incertidumbre al sujeto extraditable. ${ }^{63}$

Por otro lado, para abordar los derechos a ser oído y a la defensa, la Corte IDH explica que los procesos de extradición comprenden dos etapas: una política y otra judicial. En la primera, no hay participación efectiva de la persona involucrada al proceso de extradición, toda vez que se trata de actos discrecionales del Poder Ejecutivo, sujetos a control judicial posterior. En la parte judicial, a la persona se le toma su declaración y participa activamente en las audiencias. De conformidad con los hechos del caso, Perú contemplaba estas prerrogativas en su legislación interna y permitió al señor Wong Ho Wing participar en la fase judicial, así como acceder a los documentos, por lo que no se encontró responsabilidad internacional del Estado.

A modo de conclusión de este espacio convencional, se puede dilucidar que en procedimientos donde se encuentren inmersos migrantes, bien sea para resolver órdenes de expulsión, deportación, privación de la libertad o solicitud del estatuto de refugiado, las garantías al debido proceso y el acceso a un recurso adecuado y efectivo resultan ser imperativos para garantizar sus derechos, previo a rendir su primera declaración ante un Estado cuya normatividad es desconocida, por lo que requieren de la asistencia de un defensor público gratuito y la asistencia consular, así como pueden presen-

62 Corte IDH, Caso Wong Ho Wing vs. Perú. Excepción Preliminar, Fondo, Reparaciones y Costas. Sentencia del 30 de junio de 2015, serie C, núm. 297.párr. 208.

63 Idem. Dado a que el Estado de Perú no actuó así y el proceso de extradición se prolongó de tal forma que creó incertidumbre al señor Wong Ho Wing, se declaró su responsabilidad internacional. 
Esta revista forma parte del acervo de la Biblioteca Jurídica Virtual del Instituto de Investigaciones Jurídicas de la UNAM

tarse limitaciones frente al idioma, por tanto, tienen el derecho de acceder a los servicios de un intérprete y demás garantías establecidas.

Por todo lo anterior, los Estados tienen la obligación de otorgar un procedimiento ajustado a los principios mínimos del debido proceso, detallados específicamente en cada situación analizada, y asegurar la efectividad de los recursos disponibles, atendiendo a las necesidades concretas de protección que requiere la población migrante, a raíz de su situación de vulnerabilidad.

Así las cosas, frente al espacio convencional denominado debido proceso en los procedimientos de expulsión, devolución o deportación y solicitud de estatuto de refugiado, puede generarse el espacio citacional evidenciado en el siguiente cuadro:

\section{OC 25 de 2018}

La institución de asilo y su reconocimiento en el sistema interamericano de protección

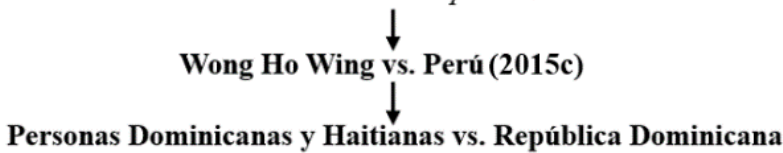

(2014b)

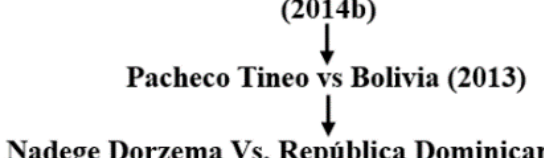

Nadege Dorzema Vs. República Dominicana (2012)

Vélez Loor vs Panamá (2010b)

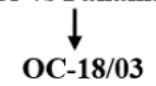

Condición Jurídica y Derechos de los Migrantes Indocumentados.

FUENTE: Elaboración propia a partir del estudio de las sentencias de la Corte IDH.

\section{Asistencia consular}

Una de las garantías judiciales que es exclusiva de las personas en situación migratoria es la asistencia consular. Al respecto, la Corte IDH ha establecido que los migrantes involucrados en un proceso adelantado por el Estado, tienen derecho, en virtud del artículo 8o. de la Convención Americana a una comunicación efectiva con el consulado de su país de origen, 
con el fin de ser asistido por éste durante el proceso. Esta obligación fue definida por la Corte Interamericana desde la Opinión Consultiva 16, de 1999, donde cita la Convención de Viena sobre relaciones consulares y sus disposiciones referentes a la posibilidad de que el cónsul:

Pueda asistir al detenido en diversos actos de defensa, como el otorgamiento o contratación de patrocinio letrado, la obtención de pruebas en el país de origen, la verificación de las condiciones en que se ejerce la asistencia legal y la observación de la situación que guarda el procesado mientras se halla en prisión. $^{64}$

De igual forma, la Corte IDH explica la relación existente entre la información sobre la asistencia consular con las garantías mínimas del debido proceso legal, argumentando que la comunicación entre el migrante y su consulado permite ejercer una mejor defensa y tener un juicio justo en observancia de la ley. Esta garantía para el migrante comprende el derecho a la información sobre la asistencia consular, derecho a la notificación y a la asistencia misma. ${ }^{65}$

Desarrollando el estándar en casos contenciosos de Ecuador ${ }^{66}$ y Argentina ${ }^{67}$ sobre detenciones a ciudadanos extranjeros, la Corte IDH establece que es necesaria la notificación de su derecho a comunicarse con un funcionario consular de su país en el momento en que es privado de su libertad y antes de que rinda su primera declaración, con el objetivo de que pueda preparar una defensa efectiva, sea asistido en el procedimiento y tenga un juicio justo, ya que hace parte de las garantías que se derivan del debido proceso legal. ${ }^{68}$

64 Corte IDH, "El derecho a la información sobre la asistencia consular en el marco de las garantías del debido proceso legal”, Opinión Consultiva OC-16/99 del 1 de octubre de 1999, serie A, núm. 16, párr. 86.

65 Idem

66 Corte IDH, Caso Tibi vs. Ecuador, cit.; Corte IDH, Caso Acosta Calderón vs. Ecuador. Fondo, Reparaciones y Costas. Sentencia del 24 de junio de 2005, serie C, núm. 129; Corte IDH, Caso Chaparro Álvarez y Lapo Íñiguez vs. Ecuador. Excepciones Preliminares, Fondo, Reparaciones y Costas. Sentencia del 26 de noviembre de 2008, serie C, núm. 189.

67 Corte IDH, Caso Bueno Alves vs. Argentina. Fondo, Reparaciones y Costas. Sentencia del 11 de mayo de 2007, serie C, núm. 164.

68 Dado que en ninguno de los casos mencionados, los Estados cumplen con la obligación de brindar esta asistencia a los migrantes, afectó su derecho a la defensa y con ello se vio 
Sin embargo, este estándar es ampliado por la Corte IDH en el caso Vélez Loor vs. Panamá, cuando desarrolla los componentes esenciales de la asistencia consular, estableciendo que el Estado debe permitir que el funcionario consular brinde servicios legales al detenido. Así, retoma lo establecido por la Convención de Viena sobre relaciones consulares, la cual dispone que el detenido tiene derecho a comunicarse libremente con los funcionarios consulares, como recibir visitas de estos, dando efectividad a los derechos a la libertad, a la integridad personal y a la defensa. ${ }^{69}$

En esta oportunidad, el Estado de Panamá acreditó que posibilitó la comunicación con los funcionarios consulares, sin embargo, el procedimiento administrativo que se llevó a cabo y que culminó con la decisión de una detención privativa de la libertad, fue previo a la visita de los funcionarios al señor Vélez Loor, por lo que se demostró que en la duración del proceso no contó con la posibilidad de presentar una defensa efectiva con la asistencia consular ni de tener un juicio contradictorio, ya que no se materializó. Por lo anterior, el Estado de Panamá fue declarado responsable por la falta de información y acceso efectivo a la asistencia consular, siendo este un componente del artículo 80 . de la Convención Americana. ${ }^{70}$

Por último, en el caso Nadege Dorzema vs. República Dominicana determinó que los extranjeros se encuentran muchas veces detenidos en un medio social y jurídico diferente, y con un idioma que desconocen, por lo que el derecho a ser asistidos a través de un cónsul garantiza que exista un debido proceso en igualdad de condiciones frente a los nacionales y goce de ambientes de detención compatibles con el respeto a la dignidad de las personas. ${ }^{71}$

En resumen, la garantía convencional de la asistencia consular implica para los Estados comunicar el derecho al migrante de ser asistido por su cónsul y garantizar la asistencia misma, antes de su primera declaración en cualquier procedimiento, con el fin de permitir el pleno ejercicio del derecho a la defensa y con ello asegurar el debido proceso.

En el siguiente cuadro, se evidencia el espacio citacional, que podría desarrollarse desde el espacio convencional denominado "asistencia consular".

comprometida su responsabilidad internacional por vulnerar el artículo 8o. de la Convención Americana.

69 Corte IDH, Caso Vélez Loor vs. Panamá, cit.

70 Idem.

71 Corte IDH, Caso Nadege Dorzema y otros vs. República Dominicana, cit. 


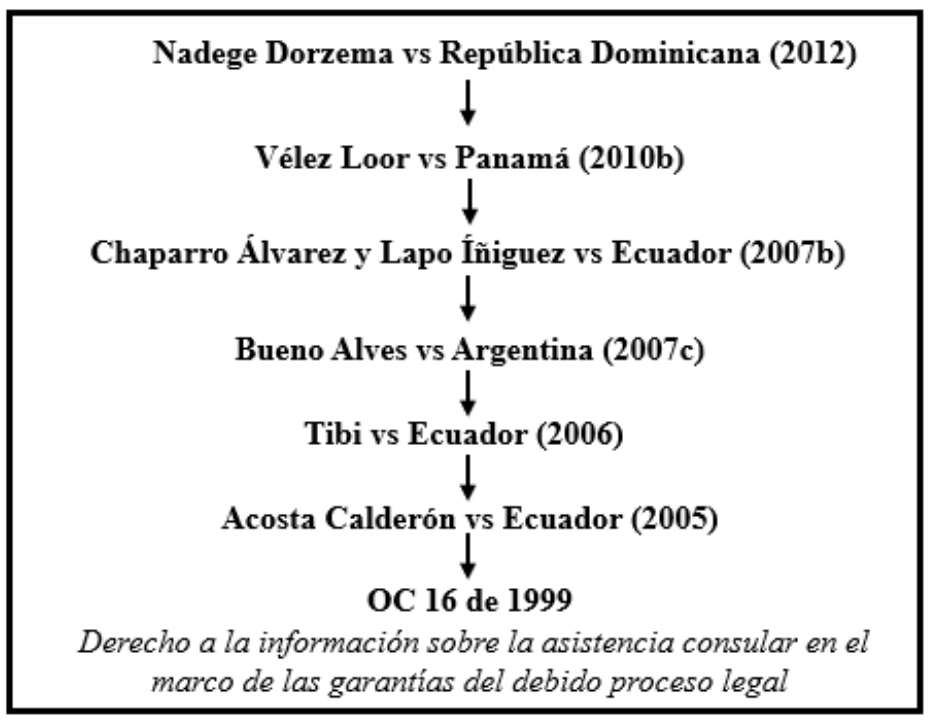

FUENTE: Elaboración propia a partir de las sentencias de la Corte IDH.

\section{Garantías de los niños y niñas en procedimientos migratorios}

La Corte IDH ha determinado que los Estados tienen la obligación de garantizar a todas las personas, la posibilidad de hacer valer sus derechos y defender sus intereses en condiciones de igualdad. ${ }^{72}$ Este deber toma mayor relevancia en aquellos procedimientos en los que se ven involucrados los niños, a quienes se les debe garantizar, teniendo en cuenta su condición de vulnerabilidad y el interés superior, los derechos contenidos en los artículos 8o. y 25 de la Convención Americana.

En relación con lo anterior, la Corte IDH en su Opinión Consultiva 17/02 determinó que el análisis de los derechos de los niños debe respetar en todo momento su interés superior, "principio que se funda en la dignidad humana, en las características propias de los niños y en la necesidad de propiciar su desarrollo"73 como sujetos de especial protección en razón a su inmadurez y vulnerabilidad.

72 Corte IDH, "Derechos y garantías de niñas y niños en el contexto de la migración y/o en necesidad de protección internacional”, Opinión Consultiva OC-21/14 del 19 de agosto de 2014, serie A, núm. 21.

73 Ibidem, párr. 56. 
Para el caso en específico de las garantías judiciales y de la protección judicial, la Corte IDH recuerda que son de observancia obligatoria para los niños y se deben correlacionar con el artículo 19 de la misma Convención Americana, ya sea en procesos administrativos o judiciales. Sin embargo, es importante destacar que a raíz de las condiciones especiales de los menores, los Estados tienen el deber de adoptar medidas de protección específicas para regular su participación en un proceso.

En este sentido, la Corte IDH menciona que las medidas de protección que se deben adoptar en sede administrativa, como es el caso de los procedimientos migratorios, deben:

Ajustarse a la ley y procurar para que el niño continué dentro de su núcleo familiar, siempre que sea posible y razonable, de lo contrario, la separación debe darse por el menor tiempo posible. Asimismo, establece que quienes intervengan en los procesos decisorios deben ser competentes para identificar las medidas que requiere el menor y que en todo caso, el uso de medidas privativas de la libertad debe ser de carácter excepcional. ${ }^{74}$

Bajo esta línea argumentativa, la OC-21 de 2014, explica, en particular, las garantías del debido proceso aplicables en los procedimientos migratorios que involucran niños y niñas. En este marco, determina que las garantías judiciales aplican a cualquier persona, independientemente de su edad y su condición de instancia. No obstante, los Estados deben tener en cuenta que este derecho se correlaciona con otros, especialmente el de los niños, el cual exige la adopción de ciertas medidas específicas con el fin de asegurar el acceso a la justicia, teniendo como eje central el interés superior del niño. ${ }^{75}$

De esta forma, la Corte IDH toma fundamentos del derecho internacional de los derechos humanos y determina las garantías que deben regir en todo proceso migratorio que involucre niños y niñas. En primer lugar, explica que se debe notificar la existencia del proceso y de la decisión a través de personal capacitado para comunicar al niño o niña, dentro de sus capacidades cognos-

74 Corte IDH, “Condición jurídica y derechos humanos del niño", Opinión Consultiva OC- 17/02 del 28 de agosto de 2002, serie A, núm. 17, párr. 103

75 Corte IDH, "Derechos y garantías de niñas y niños en el contexto de la migración y/o en necesidad de protección...”, cit. 
citivas. De igual manera, debe garantizarse que el proceso sea adelantado por un funcionario especializado, independiente e imparcial. Por otro lado, los Estados deben cumplir con la obligación de respetar el derecho de los niños y niñas a ser oídos y participar en las etapas procesales, utilizando herramientas que permitan su expresión a través de personal capacitado.

Simultáneamente, es necesario asegurar el derecho a ser asistido por un traductor o intérprete, en caso de no compartir o comprender el idioma, al igual que debe realizarse la comunicación y permitir la asistencia consular, de tal forma que el cónsul pueda velar porque las actuaciones se lleven a cabo considerando el interés superior del niño o niña. Igualmente, de forma gratuita, los Estados deben asegurar que sean asistidos por un representante legal especializado. ${ }^{76}$

Es importante destacar que la decisión que adopten los Estados en relación con el procedimiento debe estar debidamente fundada, evaluando las condiciones especiales y el interés superior del niño y la niña, quien tendrá derecho a recurrirlo en las instancias correspondientes, con efectos suspensivos, a través de los recursos que deben cumplir con las condiciones establecidas en el artículo 25 de la Convención Americana. Además, debe asegurarse que el procedimiento se lleve a cabo en un plazo razonable, tal como lo indica el artículo 8o. de la Convención, más aún en relación con los niños, sujetos de especial protección. ${ }^{77}$

En casos contenciosos como Pacheco Tineo vs. Bolivia, se ha establecido que se debe tomar en consideración el corpus juris en materia de protección de estos, a través de la Convención sobre los Derechos del Niño, la cual reconoce la oportunidad que tienen de ser oídos y participar activamente en todo procedimiento judicial o administrativo y su derecho a solicitar el estatuto de refugiado conforme a los procedimientos internacionales e internos de cada Estado, respetando su interés superior en todas las decisiones. ${ }^{78}$

Los alcances de estos derechos varían significativamente según quien sea el solicitante principal de la condición de refugiado. Por ejemplo, si el niño o niña es quien presenta la solicitud, los principios que se derivan de la Convención sobre los Derechos del Niño son aplicables en el ámbi-

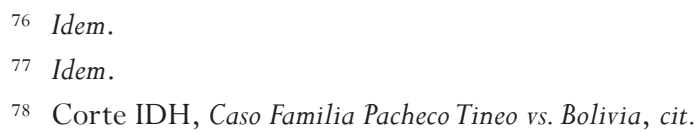


to sustancial y procedimental, propiciado por un ambiente que le genere confianza en el proceso. ${ }^{79}$

Por otro lado, si la solicitud la presenta un adulto en representación de un niño y recibe la protección, los demás miembros de su núcleo familiar pueden recibir el mismo tratamiento, en virtud del principio de la unidad familiar. Por el contrario, si la solicitud es rechazada, los familiares tienen derecho a presentar su solicitud y que sea evaluada de forma independiente. ${ }^{80}$

Ahora bien, frente al procedimiento de expulsión de migrantes en situación irregular, la Corte IDH establece que las autoridades deben tener en cuenta la relación existente entre el derecho de la protección a la familia y los derechos de los niños y las niñas. Por ello, obliga a los Estados a tomar medidas especiales que propendan a fortalecer en todo momento el núcleo familiar, por lo que la separación de los niños de sus padres, incluso siendo legal, debe respetar el principio del interés superior del niño, debe ser excepcional y temporal, independiente de si ocurre dentro del Estado que los expulsa o en el Estado al cual serán expulsados. ${ }^{81}$

Por último, el caso Personas Dominicanas y Haitianas vs. República Dominicana, establece que en los procedimientos de expulsión en los que se vean involucrados, los Estados deberán observar el interés superior, la protección de la familia y la unidad familiar, considerando la protección de los niños como eje central dentro del procedimiento. Por ello, establece que se debe tener en cuenta: i) la historia migratoria; ii) la nacionalidad, guarda y residencia de los niños, en caso de ser uno de los padres sujeto de proceso de expulsión; iii) la afectación de la ruptura familiar en la vida del niño o niña, y v) el alcance de perturbación en la vida diaria del niño. De esta forma, se garantiza a los niños y las niñas sus derechos en conexidad con las garantías y protección judiciales que exige tratamiento especial, de conformidad con el principio de interés superior. ${ }^{82}$

En conclusión, para respetar las garantías de los niños y niñas en procedimientos migratorios los Estados deben tener en cuenta como eje central el principio de interés superior de los niños y niñas, en el marco de las garantías del debido proceso, contando con personal especializado para ello.

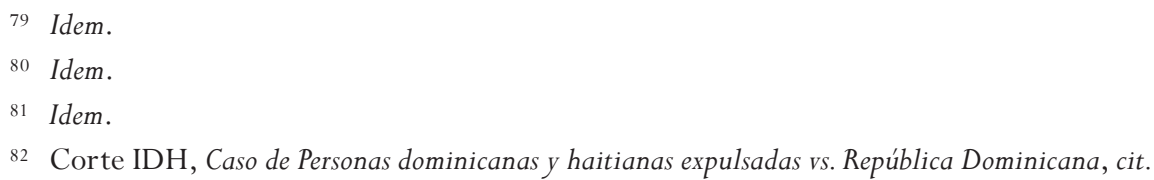


En el siguiente cuadro, se evidencia el espacio citacional, que podría desarrollarse desde el espacio convencional denominado "Garantías de los niños y niñas en procedimientos migratorios".

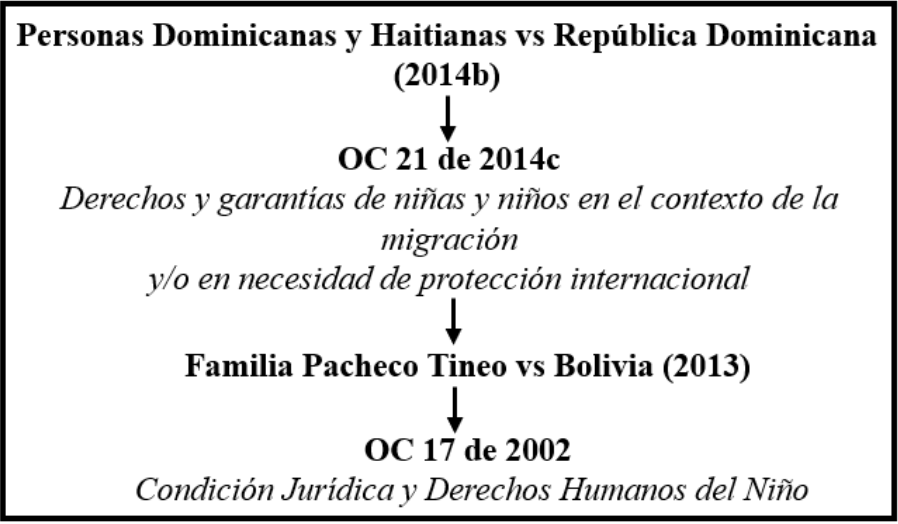

FUENTE: Elaboración propia a partir del estudio de las sentencias de la Corte IDH.

\section{CONCLUSIONES}

El control de convencionalidad es una figura que se ha desarrollado en el sistema interamericano de derechos humanos, partiendo de las decisiones de la Corte IDH, tanto en sede consultiva como en casos contenciosos. En estas decisiones el órgano judicial confronta la normativa del Estado con la Convención Americana, los instrumentos que forman del corpus iuris interamericano y todas las actuaciones que se realizan en su interior para establecer si se ajustan o no a las obligaciones de respeto, garantía y adecuación en armonía con el principio pro homine.

A partir del ejercicio de control de convencionalidad directo sobre las decisiones de la Corte IDH, es posible identificar espacios citacionales que obtiene el órgano judicial al interpretar los derechos en situaciones en concreto, espacios traducidos en reglas de derecho que al ser reiteradas se convierten en precedente interamericano de cumplimiento obligatorio para los Estados. Este ejercicio puede ser replicado en diferentes escena- 
rios con el fin de propender a la protección de los derechos humanos y contribuir al diálogo judicial entre la corte nacional y la interamericana.

Como resultado, se identificaron los estándares interamericanos de protección de los derechos contenidos en los artículos 8o. y 25 de la CADH en contextos de migración y a través de espacios citacionales obtenidos de las decisiones de la Corte IDH desde su función consultiva y contenciosa en los últimos 19 años.

A partir de lo anterior se estableció que la Corte IDH ha sentado precedentes de imperativo cumplimiento para los Estados parte de la Convención en materia de las garantías mínimas al debido proceso legal que se les deben otorgar a los migrantes, tanto en procesos judiciales como administrativos, sumado al acceso un recurso adecuado y efectivo en situaciones de deportación, expulsión, privación de la libertad, solicitud del reconocimiento del estatuto de refugiado y devolución con un enfoque diferencial hacia los niños, niñas y adolescentes.

En suma, las garantías y protección judiciales de los migrantes son derechos esenciales, cuyo ejercicio deriva en el goce de otros derechos convencionales que deben ser protegidos por los Estados a partir de un escenario de acceso real y efectivo a la justicia, así como una normatividad interna adecuada al corpus iuris interamericano en materia de derechos de migrantes desde un enfoque diferencial y sin discriminación.

\section{BibLiOgRAFÍA}

BRewer, Allan y SANTOFIMIO Jaime, Control de convencionalidad y responsabilidad del Estado, Bogotá, Universidad Externado de Colombia, 2013.

Cubides CÁRDEnAS, Jaime Alfonso, "El origen del control de convencionalidad (CCV) y sus implicaciones para los Estados que reconocen el sistema interamericano de derechos humanos (SIDH)", Ambiente Jurídico, vol. 15, 2013.

GarCía RAMÍREZ, Sergio, "Relación entre la jurisdicción interamericana y los Estados (sistemas nacionales). Algunas cuestiones relevantes”, Anuario Iberoamericano de Justicia Constitucional, núm. 18, 2014. Disponible en: https: / / dialnet.unirioja.es / servlet / articulo?codigo $=4900203$. 
García, Sergio y Morales, Julieta, "Afirmaciones y novedades en la jurisprudencia de la Corte Interamericana De Derechos Humanos (20092012)", Anuario Iberoamericano de Justicia Constitucional, núm. 17, 2013. Disponible en: https: / / recyt.fecyt.es//index.php/AIJC/article/viewFile /40786 123215.

GonZÁlez DomíngueZ, Pablo, "La doctrina del control de convencionalidad a la luz del principio de subsidiariedad”, Estudios Constitucionales, núm. 1, 2017. Disponible en: https://scielo.conicyt.cl/scielo.php?script=sci_artte $x t \& p i d=S 0718-52002017000100003$.

IBÁÑEZ RIVAS, Juana María, "El control de convencionalidad y la consolidación del ius commune interamericano", en VON BOGDANDY, Armin; MORALES, Mariela y FERRER MAC-GREGOR, Eduardo (coords.), Ius constitutionale commune en América Latina. Textos básicos para su comprensión, México, Instituto de Estudios Constitucionales del Estado de Querétaro-Max Planck Institute for Comparative Public Law and International Law, 2017. Disponible en: http: / / www.corteidh.or.cr/tablas/r36072.pdf.

Instituto InTERAmericano De DereChOs Humanos, Manual auto-formativo para la aplicación del control de convencionalidad dirigido a operadores de justicia, Costa Rica, IIDH, 2015. Disponible en: http://www.corteidh. or.cr/tablas/32077.pdf.

LóPeZ Medina, Diego, El derecho de los jueces, Bogotá, Legis Editores, 2008. Nogueira Alcalá, Humberto, "El control de convencionalidad por los Estados parte de la Convención Americana sobre Derechos Humanos y tribunales chilenos", Revista de Derecho (UCUDAL), vol. 15, núm. 1, 2017. Disponible en: http: / / www.scielo.edu.uy/pdf/rd/n15/2393-6193rd-15-00143.pdf.

Quinche RamíreZ, Manuel Fernando, El control de convencionalidad, Bogotá, Themis, 2014.

ROA, Jorge Ernesto, La función consultiva de la Corte Interamericana de Derechos Humanos, Bogotá, Universidad Externado de Colombia, 2015. 